\title{
Proapelin is processed extracellularly in a cell line-dependent manner with clear modulation by proprotein convertases
}

\author{
Kyungsoo Shin ${ }^{1} \cdot$ Michael Landsman $^{2} \cdot$ Stephanie Pelletier ${ }^{2} \cdot$ Bader N. Alamri $^{2,3,4} \cdot$ Younes Anini $^{2,3} \cdot$ Jan K. Rainey ${ }^{1,5}(0)$
}

Received: 26 June 2018 / Accepted: 28 October 2018 / Published online: 15 November 2018

(c) Springer-Verlag GmbH Austria, part of Springer Nature 2018

\begin{abstract}
Apelin is a peptide hormone that binds to a class A GPCR (the apelin receptor/APJ) to regulate various bodily systems. Upon signal peptide removal, the resulting 55-residue isoform, proapelin/apelin-55, can be further processed to 36-, 17-, or 13-residue isoforms with length-dependent pharmacological properties. Processing was initially proposed to occur intracellularly. However, detection of apelin-55 in extracellular fluids indicates that extracellular processing may also occur. To test for this, apelin-55 was applied exogenously to HEK293A cells overexpressing proprotein convertase subtilisin kexin 3 (PCSK3), the only apelin processing enzyme identified thus far, and to differentiated 3T3-L1 adipocytes, which endogenously express apelin, PCSK3 and other proprotein convertases. Analysis of culture media constituents from each cell type by high performance liquid chromatography-mass spectrometry and western blot demonstrated a time-dependent decrease in apelin-55 levels. This decrease was partially, but not fully, attenuated by PCSK inhibitor treatment in both cell lines. Comparison of the resulting apelin-55-derived peptide profile between the two cell lines demonstrated distinct processing patterns, with apelin-36 production apparent in 3T3-L1 adipocytes vs. detection of the prodomain of a shorter isoform (likely the apelin-13 prodomain, observed after additional proteolytic processing) in PCSK3-transfected HEK293A cells. Extracellular processing of apelin, with distinct cell type dependence, provides an alternative mechanism to regulate isoform-mediated physiological effects of apelin.
\end{abstract}

Keywords Apelin · Peptide hormone · Proprotein convertase subtilisin kexin · Proprotein processing · High performance liquid chromatography (HPLC) $\cdot$ Electrospray ionization time of flight mass spectrometry (ESI-MS)

Handling Editor: F. Albericio.

Electronic supplementary material The online version of this article (https://doi.org/10.1007/s00726-018-2674-8) contains supplementary material, which is available to authorized users.

Younes Anini younes.anini@dal.ca

$\bowtie$ Jan K. Rainey jan.rainey@dal.ca

1 Department of Biochemistry \& Molecular Biology, Dalhousie University, Halifax, NS B3H 4R2, Canada

2 Department of Physiology and Biophysics, Dalhousie University, Halifax, NS B3H 4R2, Canada

3 Department of Obstetrics and Gynaecology, Dalhousie University, Halifax, NS B3H 4R2, Canada

4 Department of Medicine, Dalhousie University, Halifax, NS B3H 4R2, Canada

5 Department of Chemistry, Dalhousie University, Halifax, NS B3H 4R2, Canada

$\begin{array}{ll}\text { Abbreviations } & \\ \text { AR } & \text { Apelin receptor (APJ) } \\ \text { BSA } & \text { Bovine serum albumin } \\ \text { DEXA } & \text { Dexamethasone } \\ \text { DMEM } & \text { Dulbecco's modified Eagle's medium } \\ \text { ESI-MS } & \text { Electrospray ionization mass spectrometry } \\ \text { FBS } & \text { Fetal bovine serum } \\ \text { GPCR } & \text { G protein-coupled receptor } \\ \text { HEK } & \text { Human embryonic kidney cells } \\ \text { His-apelin-55 } & \text { Human apelin-55 with N-terminal His6 } \\ & \text { tag and TEV protease cleavage site } \\ \text { IBMX } & \text { 3-isobutyl-1-methylxanthine } \\ \text { LC-MS } & \text { Liquid chromatography-mass } \\ & \text { spectrometry } \\ \text { NCS } & \text { New calf serum } \\ \text { P/S } & \text { Penicillin and streptomycin } \\ \text { PCSK } & \text { Proprotein convertase subtilisin kexin } \\ & \text { (PCSK) } \\ \text { PRCP } & \text { Prolylcarboxypeptidase } \\ \text { Pyr } & \text { Pyroglutamate }\end{array}$




$\begin{array}{ll}\text { RP-HPLC } & \begin{array}{l}\text { Reverse phase high performance liquid } \\ \text { chromatography } \\ \text { Sodium dodecyl sulfate polyacrylamide } \\ \text { gel electrophoresis }\end{array} \\ \text { SEM } & \begin{array}{l}\text { Standard error of the mean } \\ \text { Trifluoroacetic acid }\end{array} \\ \text { TFA } & \text { Tris-buffered saline with } 0.1 \% \text { Tween-20 }\end{array}$

\section{Introduction}

Apelin is a cognate peptide hormone for the class A G-protein coupled receptor (GPCR) called the apelin receptor (AR, formerly APJ). Both apelin and the AR are widely expressed in the body, including in the central nervous system, cardiovascular system, and other peripheral locations such as adipose and muscle tissues (Shin et al. 2018). Consequently, apelin is known to regulate various physiological systems. Its effects include modulation of heart contractility, vasodilation, and glucose homeostasis. In turn, its potential for therapeutic application means that apelin has been a highly sought after medicinal chemistry target (Narayanan et al. 2015).

Cleavage of a 22-residue signal peptide from the 77-residue human apelin expression product (typically termed preproapelin) produces apelin-55 (Table 1). Apelin-55 has traditionally been referred to as proapelin, although this nomenclature is not consistent with its recently demonstrated (Shin et al. 2017a) bioactivity. The apelin-55 sequence contains multiple dibasic amino acid motifs (Tatemoto et al. 1998), indicative of the potential involvement of proprotein convertase subtilisin kexin (PCSK)-mediated processing (Seidah and Prat 2012) to produce 36-, 17-, and 13-residue isoforms (Table 1). All isoforms include the C-terminal residues of their shared unprocessed protein, required for receptor binding and activation (Shin et al. 2018).

In support of PCSK involvement in apelin processing, we previously demonstrated that apelin-55 can be processed by PCSK3 (furin) in vitro (Shin et al. 2013). Notably,
PCSK3-mediated processing of apelin-55 was direct and preferential, with only apelin-13 produced. Despite similar dibasic site cleavage motifs, no additional longer apelin isoforms could be detected by liquid chromatography-mass spectrometry (LC-MS), and neither PCSK1 (PC1/3) nor PCSK7 (PC7) could process apelin-55 in vitro. Apelin-36 has since also been shown to be processed by PCSK3 (Adam et al. 2016).

Although their conformations are highly similar in solution, indicative of similar modes of AR activation (Shin et al. 2017a), apelin isoforms present length-dependent variation in receptor affinity, signaling, and cellular effects (Tatemoto et al. 1998; Habata et al. 1999; Shin et al. 2017a). For example, apelin-13 rapidly dissociates from the receptor upon internalization, leading to receptor recycling (Evans et al. 2001; Lee et al. 2010). In contrast, apelin-36-AR interaction leads to receptor degradation with the ligand and receptor remaining associated upon internalization (Lee et al. 2010). This phenomenon is consistent with the higher receptor affinity reported for the longer isoform (Habata et al. 1999). These disparities mean that the ratio of apelin isoforms present in a given setting has been hypothesized to regulate the physiological effects of apelin (Lee et al. 2010).

Apelin-55 was not detected when apelin was first identified in bovine stomach tissue extract (Tatemoto et al. 1998). Instead, apelin-36 was the longest isoform identified. Consequently, apelin-55 was labeled as an inactive proprotein and apelin-77 as its preproprotein. These observations, collectively, led to the hypothesis that apelin processing occurred intracellularly, with apelin-36 produced from the 55-residue proprotein isoform, followed by subsequent processing to the shorter and more potent apelin-13 or -17 isoforms (Kleinz and Davenport 2005; Habata et al. 1999). In support of intracellular processing, co-expression of apelin and PCSK3 led to observable cleavage of apelin into shorter isoforms (Adam et al. 2016). However, the detection of intact apelin-55 in colostrum and milk (Mesmin et al. 2011) and of isoforms with mass greater than apelin-36 in plasma (Foldes et al. 2003) suggest that intracellular processing to apelin-36 is

Table 1 Apelin isoform amino acid sequences

\begin{tabular}{ll}
\hline Identity & Amino acid sequence* \\
\hline Apelin-77 (Preproapelin) & MNLRLCVQALLLLWLSLTAVCGGSLMPLPDGNGLEDGNVRHLVQPRGSRNGPGP- \\
& WQGGRRKFRRQRPRLSHKGPMPF \\
Apelin-55 (Proapelin) & GSLMPLPDGNGLEDGNVRHLVQPRGSRNGPGPWQGGRRKFRRQRPRLSHKGPMPF \\
Apelin-36 & LVQPRGSRNGPGPWQGGRRKFRRQRPRLSHKGPMPF \\
Apelin-17 & KFRRQRPRLSHKGPMPF \\
Apelin-13 & QRPRLSHKGPMPF \\
Pyr-apelin-13 & $<$ ERPRLSHKGPMPF \\
\hline
\end{tabular}

*Underlined residues in preproapelin represent the signal peptide; <E represents the N-terminal pyroglutamate that is spontaneously formed from glutamine 
not ubiquitous. Correspondingly, we recently demonstrated that apelin-55 activates the AR (Shin et al. 2017a).

Secretion of intact apelin-55 means that this isoform may directly interact with endoproteases on the cell surface or another extracellular context to undergo enzymatic processing. In support of this, while apelin-36 was detected in the mixture of bioactive peptides purified from bovine stomach tissues (Tatemoto et al. 1998), only Pyr-apelin-13 (apelin-13 with an N-terminal pyroglutamate) was detectable from glucose-stimulated gastric secretion in mice (Dray et al. 2013). Thus, if apelin-36 is the form released from stomach cells, the detection of differing isoforms in gastric secretions implies that processing may occur extracellularly. Furthermore, while injection of apelin-36 or -13 resulted in an antithrombotic response, an apelin-36 mutant incapable of being processed by PCSKs elicited no response, indicating that apelin-36 must be processed to the 13-residue form upon injection for this activity (Adam et al. 2016).

Although there are likely multiple proteases capable of processing apelin to shorter bioactive forms, as distinct from proteases known to produce inactive or less active forms (Vickers et al. 2002; McKinnie et al. 2016; Wang et al. 2016; Kehoe et al. 2016), only PCSK3 has, thus far, been demonstrated to process apelin (Shin et al. 2013; Adam et al. 2016). This proprotein convertase is expressed ubiquitously (Seidah 2011; Thomas 2002). It can be membrane-anchored through a transmembrane domain, either in the secretory pathway or on the cell surface (Teuchert et al. 1999; Mayer et al. 2003, 2004). Alternatively, it may be shed into the extracellular fluid upon transmembrane domain cleavage (Vidricaire et al. 1993; Molloy et al. 1999). Either the membrane-anchored or shed forms of PCSK3 would potentially allow for extracellular processing. This follows precedents of extracellular processing of anthrax toxin (Klimpel et al. 1992), human immunodeficiency virus type I protein Vpr (Xiao et al. 2008), pro-ADAMTS9 (Koo et al. 2006), and B-type natriuretic peptide (Semenov et al. 2010). Notably, various apelin isoforms also bind to membrane-mimetic micelles (Langelaan and Rainey 2009; Shin et al. 2017b), further increasing the likelihood of apelin-PCSK3 interactions on the cell surface through the combination of factors proposed to increase favorability of peptide-receptor interactions in the "membrane catalysis" mechanism (Sargent and Schwyzer 1986).

All of these factors imply strong potential for extracellular apelin processing by cell surface enzymes such as PCSK3. To test for this, we exposed exogenous hexahistidine ( His $_{6}$ )-tagged apelin-55 to PCSK3-overexpressing human embryonic kidney (HEK293A) cells, providing a situation with a high probability of observing extracellular processing. Apelin processing was also tested upon exposure to differentiated 3T3-L1 adipocytes, which express both apelin and PCSK3 endogenously (Shin et al. 2013) and which have been extensively used to study the role of apelin in adipoinsular axis at both cellular and molecular level (Yue et al. 2011; Than et al. 2012, 2015; Masaki et al. 2012). The culture medium from each cell line was characterized through reverse phase high performance LC (RP-HPLC), electrospray ionization MS (ESI-MS), and western blotting to determine both the extent and isoform specificity of extracellular apelin processing taking place in each context.

\section{Materials and methods}

\section{His-apelin-55 production and purification}

Human apelin-55 with an N-terminal $\mathrm{His}_{6}$ tag and TEV protease cleavage site (His-apelin-55; total 75 residues) was expressed in Escherichia coli $\mathrm{C} 41$ (DE3) and purified using Ni-NTA affinity and cation exchange chromatography, employing minor modifications to previous protocols (Shin et al. 2013). Briefly, the protein was purified by cation exchange chromatography without TEV protease cleavage to provide an $\mathrm{N}$-terminally $\mathrm{His}_{6}{ }_{6}$-tagged apelin-55 amenable to downstream antibody-based detection. The $\mathrm{His}_{6}$-tagged peptide was further purified using RP-HPLC, as detailed previously (Shin et al. 2017a), using a ProStar HPLC (Varian Canada Inc.) equipped with a preparative $\mathrm{C}_{18}$ column (20 mm I.D. $\times 250 \mathrm{~mm}$, Cosmosil, Nacalai USA Inc.), with a binary solvent system $\left(A: \mathrm{H}_{2} \mathrm{O}\right.$ with $0.1 \%$ trifluoroacetic acid (TFA) and $\mathrm{B}$ : acetonitrile with $0.1 \%$ TFA; flow rate $8 \mathrm{~mL} / \mathrm{min}$ ). Gradients were as follows: (i) $2-20 \%$ solvent $\mathrm{B}$ in $5 \mathrm{~min}$, (ii) $20-45 \%$ solvent $\mathrm{B}$ in $25 \mathrm{~min}$, (iii) $45-2 \%$ solvent B in 1 min. Eluent peaks were collected, lyophilized, and analyzed by ESI-MS (Mass Spectrometry Laboratory, Dalhousie University). Lyophilized, purified His-apelin-55 aliquots were prepared based upon the Beer Lambert law $\left(\mathrm{c}=\mathrm{A} \cdot \varepsilon^{-1} \cdot l^{-1}\right.$, where $\mathrm{A}$ is absorbance at a given wavelength $(280 \mathrm{~nm}), \varepsilon_{280 \mathrm{~nm}}=6990 \mathrm{M}^{-1} \mathrm{~cm}^{-1}$ is the molar absorptivity at $280 \mathrm{~nm}$ for the fusion protein calculated as described by Gill and von Hippel (Gill and von Hippel 1989), and $l$ is the pathlength).

\section{Cell culture}

HEK293A cells (ATCC) were cultured at $37{ }^{\circ} \mathrm{C}$ in $5 \% \mathrm{CO}_{2}$ in Dulbecco's modified Eagle's medium (DMEM, SigmaAldrich) containing 10\% fetal bovine serum (FBS, Invitrogen, USA), $1 \%$ penicillin and streptomycin (P/S, P4333, Sigma-Aldrich). 3T3-L1 preadipocytes (ATCC) were cultured at $37{ }^{\circ} \mathrm{C}$ in $5 \% \mathrm{CO}_{2}$ in high glucose DMEM containing $10 \%$ new calf serum (NCS, Invitrogen) and $1 \% \mathrm{P} / \mathrm{S}$. The medium for both cell lines was refreshed every second day, with transfer accomplished by $10 \%$ trypsin digest when cells were at $\sim 70 \%$ confluence. 


\section{HEK293A culture and transfection}

HEK293A cells were seeded in 12-well plates and cultured in high glucose DMEM containing 1\% P/S and 10\% FBS. At $\sim 80 \%$ confluency, they were transfected by addition of serum-free $625 \mu \mathrm{L}$ of Opti-MEM (High Glucose, Gibco) containing $1 \mu \mathrm{g}$ of the PCSK 3 coding pIRES2-EGFP plasmid (gift of Drs. Michel Chrétien and Janice Mayne, University of Ottawa) and $2.5 \mu \mathrm{L}$ of Lipofectamine 2000 (Invitrogen) per well. Exposure to transfection medium was carried out for $5 \mathrm{~h}$, then medium was replaced with high glucose DMEM containing 10\% FBS. Transfected cells were allowed to express the PCSK3 gene for $48 \mathrm{~h}$ prior to use in the extracellular processing assay. To check the efficiency of transfection, total RNA was extracted from HEK293A cells using Aurum $^{\mathrm{TM}}$ Total RNA Fatty and Fibrous Tissue Kit (Bio-Rad) according to the manufacturer's protocol. Total RNA was reverse transcribed using the iScript ${ }^{\mathrm{TM}}$ cDNA Synthesis Kit (Bio-Rad) and PCSK3 mRNA was amplified by polymerase chain reaction (primers - forward: 5'-AACAACGGTGTC TGTGGTGTAGGT-3'; reverse: 5'-AGCTGGCACTGTAGA TGTGGATGT-3').

\section{T3-L1 preadipocyte differentiation}

3T3-L1 preadipocytes were seeded in 12-well plates and cultured to confluence. At 2 days post-confluence (day 0), the medium was changed to induction medium (DMEM, 10\% FBS, $1 \%$ P/S, $1 \mu \mathrm{M}$ dexamethasone (DEXA, D2915, SigmaAldrich), $0.5 \mathrm{mM}$ 3-isobutyl-1-methylxanthine (IBMX, I7018, Sigma-Aldrich), and $1 \mu \mathrm{g} / \mathrm{ml}$ human insulin (HI-210, Eli Lilly and Company). After 2 days of incubation (day 2), the medium was replaced with insulin medium (DMEM supplemented with $10 \% \mathrm{FBS}, 1 \% \mathrm{P} / \mathrm{S}$, and $10 \mu \mathrm{g} / \mathrm{ml}$ human insulin). Thereafter, the medium was replaced every day with FBS medium (DMEM supplemented with 10\% FBS and $1 \% \mathrm{P} / \mathrm{S}$ ). Once full differentiation was observed (day $8-10$ ), adipocytes were used for extracellular apelin-55 processing assays.

\section{Extracellular apelin-55 processing assay}

Following the final step of cell setup (HEK293A transfection or 3T3-L1 differentiation), His-apelin-55 was dissolved $(3 \mu \mathrm{g} / \mu \mathrm{L} ; 358 \mu \mathrm{M})$ in phenol red-free DMEM (High Glucose, Sigma-Aldrich). Medium was replaced with serumfree and phenol red-free DMEM (High Glucose, $400 \mu \mathrm{L} /$ well). Each well of the plate was supplemented with dissolved protein $(50 \mu \mathrm{L})$ at a final concentration of $0.333 \mu \mathrm{g} /$ $\mu \mathrm{L}$ per well. Cells were exposed to His-apelin-55 for designated time points. For inhibition studies, cells were exposed to decanoyl-RVKR-CMK (Biomol International) in serumfree and phenol red-free DMEM (High Glucose, $400 \mu \mathrm{L} /$ well) at concentrations of $25,2.5$, or $0.25 \mu \mathrm{M}$ for $1 \mathrm{~h}$ prior to supplementation with His-apelin-55. For $0 \mathrm{~h}$ (control) samples, the culture medium was collected promptly upon addition of His-apelin-55; thus, exposure to His-apelin-55 was short $(\leq \sim 1 \mathrm{~min})$. For all other treatments, the culture medium was collected at the designated incubation periods. All treatments were carried out in triplicate and all experiments were at least in duplicate. A high inhibitor treatment $(25 \mu \mathrm{M})$ was used as a control for all inhibitor experiments.

\section{RP-HPLC-MS based detection}

Culture media samples were resolved using a ProStar HPLC employing a $\mathrm{C}_{18}$ analytical column (4.6 mm I.D. $\times 150 \mathrm{~mm}$, Grace Alltech) and a binary solvent system $\left(\mathrm{A}: \mathrm{H}_{2} \mathrm{O}\right.$ with $0.1 \%$ trifluoroacetic acid (TFA) and $\mathrm{B}$ : acetonitrile with $0.1 \% \mathrm{TFA}$; flow rate $1 \mathrm{~mL} / \mathrm{min}$ ) with gradient elution as follows: (i) $2-20 \%$ solvent B in 5 min, (ii) $20-40 \%$ solvent B in $20 \mathrm{~min}$, (iii) $40-100 \%$ solvent B in $15 \mathrm{~min}$, (iv) $100-2 \%$ solvent $B$ in 1 min. UV chromatograms were recorded at 213 and $280 \mathrm{~nm}$ simultaneously. Non-culture media eluents were collected and pooled for each experiment then lyophilized. Eluent masses were then determined using ESI-MS (Mass Spectrometry Laboratory, Dalhousie University; instrument background shown for reference in Fig. S1) and compared to all masses that could theoretically result from post-translational processing of His-apelin-55 for identification.

\section{Western blotting-mediated detection}

For detection of extracellular His-apelin-55, $30 \mu \mathrm{L}$ of collected culture media from each well $(\sim 10 \mu \mathrm{g}$ protein load, based on initial His-apelin-55 concentration prior to cell exposure) were resolved by SDS-PAGE (20\% polyacrylamide gel, $120 \mathrm{~V}, 2 \mathrm{~h}$ ) for each experiment. The resulting gel was transferred to a polyvinylidene difluoride (PVDF) membrane (Bio-Rad) at $100 \mathrm{~V}$ for $45 \mathrm{~min}$. Membranes were blocked in Tris-buffered saline with $0.1 \%$ Tween-20 (TBST) containing $25 \mathrm{mg} / \mathrm{ml} \mathrm{BSA}$ for $60 \mathrm{~min}$ at room temperature and then washed twice with TBST for 10 min each before incubation with HisProbe-HRP (Thermo Fisher Scientific; 1:5000 dilution in TBST with $25 \mathrm{mg} / \mathrm{ml} \mathrm{BSA)} \mathrm{for} 60 \mathrm{~min}$. Subsequently, membranes were washed with TBST four times for 5 min each then incubated in Clarity Western ECL Blotting Substrates (Bio-Rad). Chemiluminescence was detected and His-apelin-55 band density was quantified using a molecular imager (Gel Doc ${ }^{\mathrm{TM}} \mathrm{XR}+$, Bio-Rad). Each quantified value was standardized to the intensity of the unprocessed His-apelin-55 control lane (i.e., 0 h) for the respective membrane blot. The standardized values from all experiments were then combined for statistical analyses. Results are presented as mean \pm standard error of the mean (SEM) and were analyzed using the $t$ test to compare each 
inhibitor treatment to the control at $0 \mathrm{~h}$ (a significance of $P<0.05$ was applied).

\section{Results}

\section{His-apelin-55 is processed upon extracellular introduction to HEK293A cells}

To evaluate potential products arising from exogenous Hisapelin-55 [mass (Table 2) confirmed by ESI-MS (Fig. S2)] processing, culture media constituents were resolved by RPHPLC. The level of intact His-apelin-55 was significantly decreased upon incubation in medium with HEK293A cells as a function of the duration of exposure (Fig. 1 and Fig. S3). Processing to specific isoforms was also implied, given the appearance of multiple new eluent peaks from $\sim 15$ to $20 \mathrm{~min}$ corresponding to RP-HPLC water:acetonitrile proportions previously observed for apelin isoform elution (Shin et al. 2013). These changes were dependent on cell exposure, as level of His-apelin-55 remained stable in cell-free culture medium (Fig. S4), consistent with our previous findings on apelin-55 stability in various buffer-based experimental conditions (Shin et al. 2013; Shin et al. 2017a).

Increased PCSK3 levels in HEK293A cells by transient transfection (Fig. S5) also decreased the His-apelin-55 level, without affecting the processing pattern in comparison to non-transfected cells (Fig. 1). Despite this decrease in Hisapelin-55 level, the eluent peaks resulting from processing were not observed to correspondingly increase. To maximize the yield of extracellular apelin processing under these experimental conditions, PCSK3-transfected HEK293A cells were used for subsequent experiments.

ESI-MS analysis was carried out for the eluent peaks collected during RP-HPLC separation (masses of all potential processing products considered are detailed in Table S1). The second largest peak at an elution time of $\sim 17 \mathrm{~min}$ had a mass corresponding to His-apelin-55 15 (Table 2, Fig. S6). The eluent at $\sim 17.5 \mathrm{~min}$ corresponded to a peptide with a mass consistent with His-apelin-55 32 (Table 2, Fig.
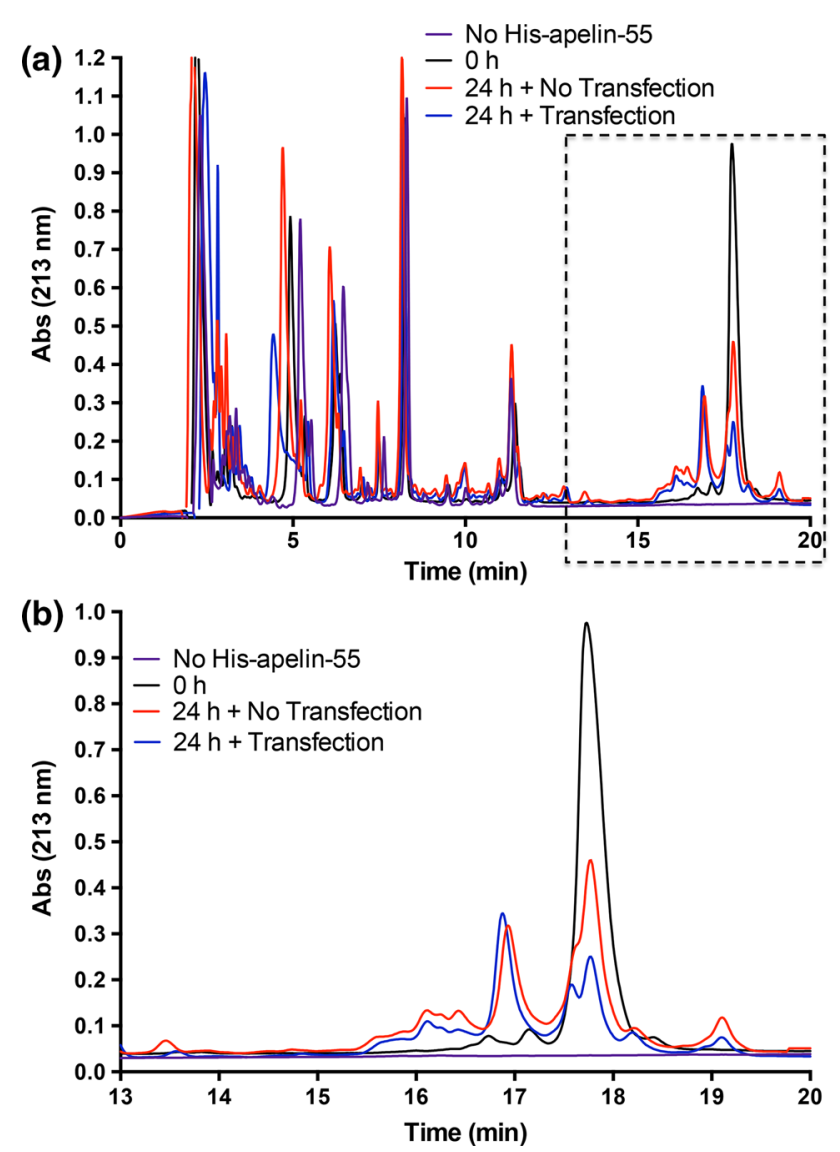

Fig. 1 HEK293A cells process exogenous His-apelin-55 (eluent peak at $18 \mathrm{~min}$ ) in a PCSK3-dependent manner. a, b Representative RP-HPLC chromatograms of cell culture media supplemented with exogenous His-apelin-55. After incubation with HEK293A cells, the resulting supernatant was resolved using a $\mathrm{C}_{18}$ analytical RP-HPLC column (linear gradient from 2 to $45 \%$ acetonitrile in $0.1 \%(\mathrm{v} / \mathrm{v})$ aqueous TFA). b Expansion of the 13-20 min RP-HPLC chromatograms from panel a (indicated by dashed box)

S7 and Fig. S8). Eluents over the 15-16.5 min exhibited convoluted $\mathrm{m} / \mathrm{z}$ ratios corresponding to various processed products (Table S1, Fig. S9 and Fig. S10). Similar to the eluent at $17 \mathrm{~min}$, His-apelin-55 cleavage products consistent with many of these corresponded to loss of $15 \mathrm{C}$-terminal

Table 2 Nomenclature, mass, and amino acid sequence of major exogenous His-apelin-55 processing products observed after incubation in HEK293A cell or 3T3-L1 adipocyte culture medium

\begin{tabular}{|c|c|c|}
\hline Name & Mass (Da) & Amino acid sequence* \\
\hline His-apelin-55 & 8380 & $\frac{\text { SGSHHHHHHGSSGENLYFQSGSLMPLPDGNGLEDGNVRHLVQPRGSRNGPGPWQGGRRK- }}{\text { FRRQRPRLSHKGPMPF }}$ \\
\hline His-apelin- $55 \Delta 1$ & 8233 & $\begin{array}{l}\frac{\text { SGSHHHHHHGSSGENLYFQSGSLMPLPDGNGLEDGNVRHLVQPRGSRNGPGPWQGGRRK- }}{\text { FRRQRPRLSHKGPMP }}\end{array}$ \\
\hline His-apelin- $55 \Delta 15$ & 6335 & SGSHHHHHHGSSGENLYFQSGSLMPLPDGNGLEDGNVRHLVQPRGSRNGPGPWQGGRRKF \\
\hline His-apelin- $55 \Delta 32$ & 4202 & SGSHHHHHHGSSGENLYFQSGSLMPLPDGNGLEDGNVRHLVQP \\
\hline His-apelin- $55 \Delta 36$ & 4196 & SGSHHHHHHGSSGENLYFQSGSLMPLPDGNGLEDGNVRH \\
\hline
\end{tabular}

*Underlined residues represent $\mathrm{N}$-terminal $\mathrm{His}_{6}$ tag and $\mathrm{TEV}$ protease cleavage site 
residues, but with additional $\mathrm{N}$ - and, in some cases, up to 16 C-terminal truncations (Table S1).

\section{PCSK inhibitor decreases the quantity of processing}

To further test the putative role of PCSK3 in the observed extracellular processing of His-apelin-55, the inhibitor decanoyl-RVKR-CMK was employed. This compound is a general PCSK inhibitor and has been previously shown to effectively inhibit processing activity of various PCSK subtypes, including PCSK3, both intracellularly and at the cell surface (Koo et al. 2006; Remacle et al. 2010). Addition of decanoyl-RVKR-CMK to the culture medium of PCSK3overexpressing HEK293A cells decreased exogenous Hisapelin-55 processing, as was evident by HPLC elution and western blotting profiles (Figs. 2, 3a). Densitometry demonstrated statistically significant inhibition with both 25
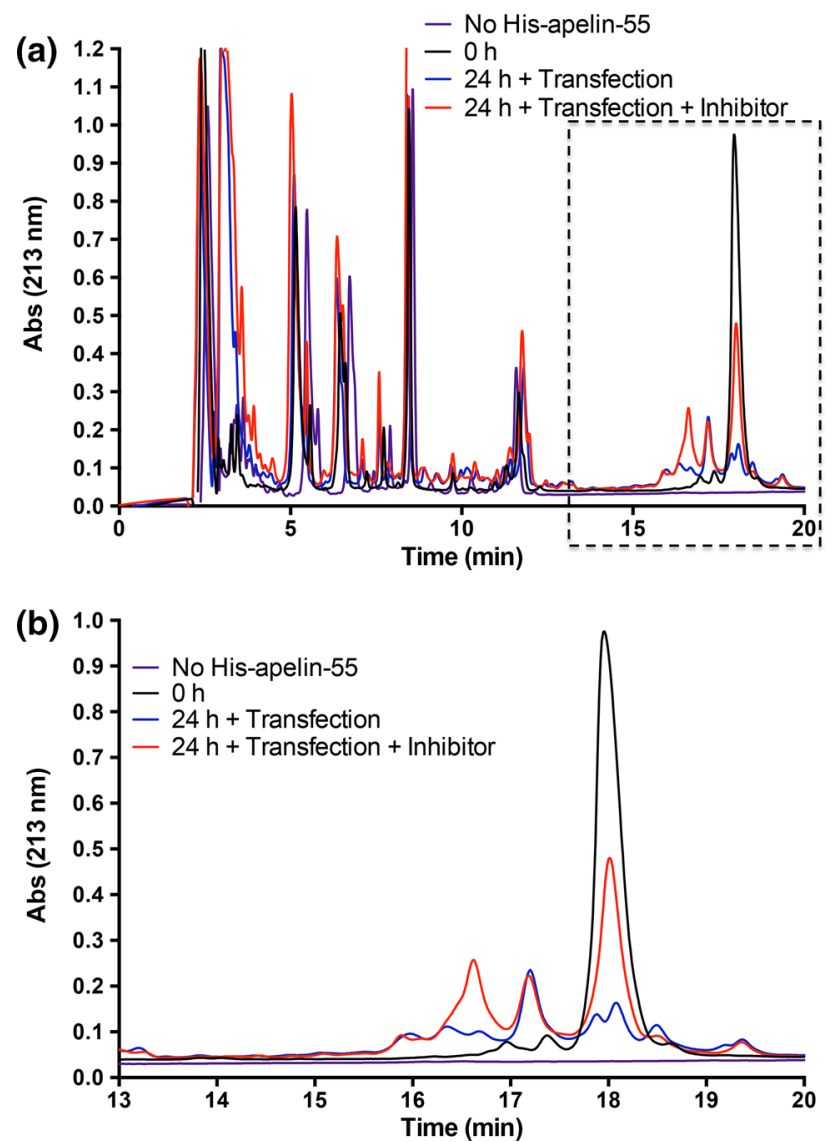

Fig. 2 The PCSK inhibitor decanoyl-RVKR-CMK alters exogenous His-apelin-55 processing by HEK293A cells overexpressing PCSK3. a, b Representative RP-HPLC chromatograms of culture media of cells pretreated with the inhibitor for $1 \mathrm{~h}$ prior to supplementing with exogenous His-apelin-55. The resulting supernatant was resolved using a $\mathrm{C}_{18}$ analytical RP-HPLC column (linear gradient from 2 to $45 \%$ acetonitrile in $0.1 \%(\mathrm{v} / \mathrm{v})$ aqueous TFA). b Expansion of the 13-20 min RP-HPLC chromatograms from panel a (indicated by dashed box)
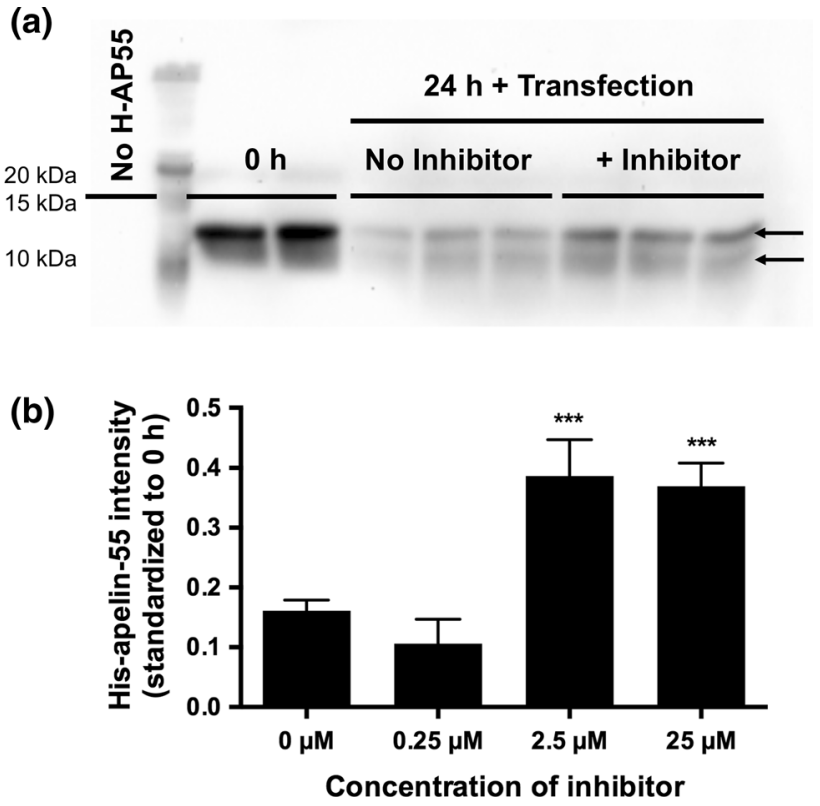

Fig. 3 Decanoyl-RVKR-CMK inhibits exogenous His-apelin-55 processing by HEK293A cells overexpressing PCSK3. Cells were pretreated with the indicated concentrations of PCSK inhibitor for $1 \mathrm{~h}$ prior to supplementing culture media with exogenous His-apelin-55. a Representative western blot. After the indicated incubation time, culture media were collected and a $30 \mu \mathrm{L}$ sample of the medium from each well $(\sim 10 \mu \mathrm{g}$ protein load, based on His-apelin-55 concentration prior to cell exposure) was resolved by SDS-PAGE and transferred onto PVDF membrane for blotting ( $n=3$ wells, $N \geq 2$ experiments). Arrows denote the unprocessed (upper) and processed (lower) His-apelin peptides. b Densitometry-based intensities of Hisapelin- 55 bands normalized to the respective $0 \mathrm{~h}$ control. Results are mean \pm SEM of the normalized values. Statistical significance $(t$ test; $* * * P<0.001)$ of each PCSK inhibitor dost was tested with respect to the $0 \mu \mathrm{M}$ control

and $2.5 \mu \mathrm{M}$ inhibitor doses (Fig. 3b); however, pretreatment with the inhibitor even at the higher of these doses did not completely block processing. Namely, despite a single apparent peak at $\sim 19$ min, a species consistent with Hisapelin-55 $\Delta 2$ remained detectable by ESI-MS (Table 2, Fig. S11), implying that this processing product is still present, though not observed through UV absorption-based monitoring of HPLC elution. Notably, HPLC chromatograms also exhibited a prominent elution peak at $\sim 16$ min with the addition of inhibitor (Fig. 2) with a mass consistent with His-apelin-55 1 (Table 2, Fig. S12; Table S2 provides all masses considered).

\section{His-apelin-55 is processed by 3T3-L1 adipocytes}

Exogenous His-apelin-55 processing was also examined in the presence of 3T3-L1 adipocytes. Given that mRNA expression of PCSK1, 3, and 7 increase in 3T3-L1 cell line upon differentiation (Shin et al. 2013), fully differentiated 3T3-L1 adipocytes were tested for extracellular apelin-55 
processing due to the correspondingly increased likelihood of PCSK-mediated processing. Similarly to incubation with HEK293A cells, incubation with differentiated adipocytes decreased the level of exogenous His-apelin-55 following 24 h (Figs. 4, 5 and Fig. S13).

HPLC analysis of adipocyte culture medium exhibited striking differences relative to HEK293A culture medium. Specifically, the elution profile of His-apelin-55 and its processed products widened to a range of $\sim 13-20 \mathrm{~min}$ (Fig. 4), the overall chromatographic resolution was lowered, and the number of distinguishable peaks decreased. Analysis of the resulting eluents by ESI-MS also demonstrated distinct products from those observed in HEK293A culture medium (Table S3 details all processing products and masses considered for adipocyte culture medium). In particular, the product eluting at $\sim 16$ min exhibited a mass corresponding to His-apelin-55 $\Delta 36$ (Table 2, Fig. S14). Consistent with this,
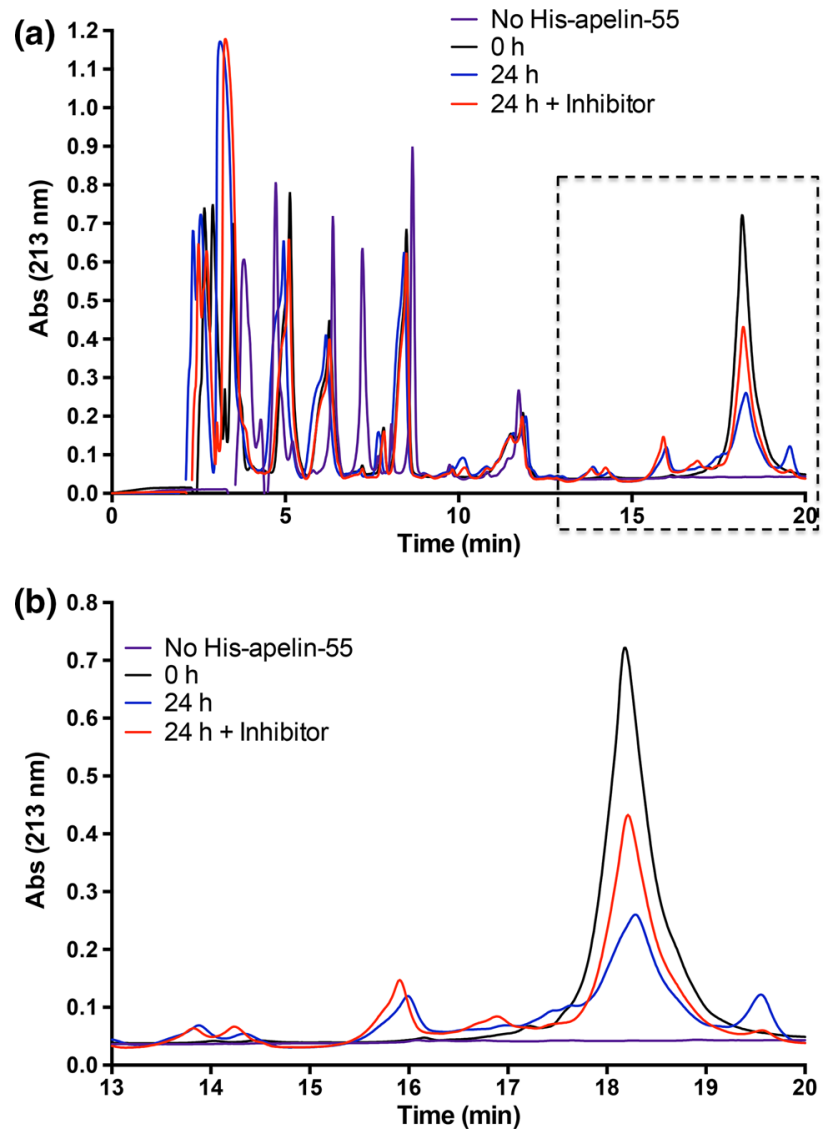

Fig. 4 Exogenous His-apelin-55 is processed by 3T3-L1 adipocytes and can be inhibited by decanoyl RVKR-CMK. a, b Representative RP-HPLC chromatograms. Cells were pretreated with the inhibitor for $1 \mathrm{~h}$ prior to supplementing culture media with exogenous His-apelin-55. The resulting supernatant was resolved using a $\mathrm{C}_{18}$ analytical RP-HPLC column (linear gradient from 2 to $45 \%$ acetonitrile in $0.1 \%$ (v/v) aqueous TFA). b Expansion of the 13-20 min RP-HPLC chromatograms from panel a (indicated by dashed box)

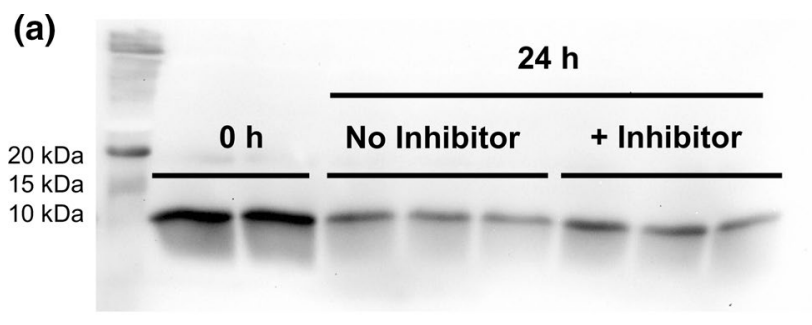

(b)

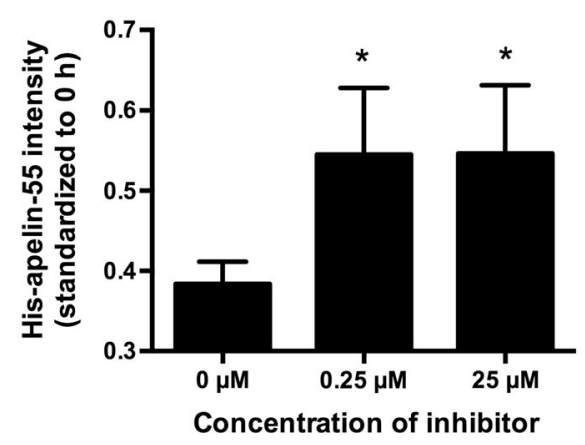

Fig. 5 Decanoyl-RVKR-CMK inhibits exogenous His-apelin-55 processing by $3 \mathrm{~T} 3-\mathrm{L} 1$ adipocytes. Cells were incubated with the indicated concentrations of PCSK inhibitor for $1 \mathrm{~h}$ prior to supplementing culture medium with exogenous His-apelin-55. a Representative western blot. After indicated incubation time, cultured media were collected and a $30 \mu \mathrm{L}$ sample of the medium from each well $(\sim 10 \mu \mathrm{g}$ protein load, based on His-apelin-55 concentration prior to cell exposure) was resolved by SDS-PAGE and transferred onto PVDF membrane for blotting ( $n=3$ wells, $N \geq 2$ experiments). b Densitometrybased intensities of His-apelin-55 bands normalized to the respective $0 \mathrm{~h}$ control. Results are mean \pm SEM of the normalized values. Statistical significance $(t$ test; $* * * P<0.001$ ) of each PCSK inhibitor dost was tested with respect to the $0 \mu \mathrm{M}$ control

the eluents from 13 to 15 min exhibited masses matching apelin-31 and -36, respectively (Fig. S15).

Pretreatment of 3T3-L1 adipocytes with decanoylRVKR-CMK again reduced, but did not completely block, His-apelin-55 processing (Fig. 5). In contrast to HEK293A culture medium, where a minimum inhibitor dose of $2.5 \mu \mathrm{M}$ was required, a dose of $0.25 \mu \mathrm{M}$ effectively inhibited Hisapelin-55 processing in 3T3-L1 culture medium (Fig. 5b). Also distinct from HEK293A cells (Fig. 3a), lower molecular weight bands indicative of new $\mathrm{His}_{6}$-reactive processing products were not observed by western blotting in adipocyte culture medium (Fig. 5a).

\section{Discussion}

The potential for extracellular processing of apelin in vivo is plausible when coupling: (1) the extracellular detection of all canonical bioactive apelin isoforms (Table 1) including apelin-55 (Foldes et al. 2003; De Mota et al. 2004; Miettinen et al. 2007; Azizi et al. 2008; Mesmin et al. 2011; Zhen et al. 2013) with (2) the potential for PCSKs to be 
cell surface-anchored and/or circulating (Seidah 2011) and (3) PCSK-mediated processing of exogenous proteins (Xiao et al. 2008; Semenov et al. 2010; Klimpel et al. 1992). Processing in this manner would alter the balance of isoforms in proximity to the receptor. Given isoform-dependent pharmacology (Tatemoto et al. 1998; Shin et al. 2017a; Lee et al. 2010), this would, in turn, affect downstream signaling.

When incubated with HEK293A cells, exogenous Hisapelin-55 was processed to a number of shorter forms (blue arrows, Fig. 6). This exhibited a PCSK3-dependence, as processing was increased with PCSK3 transfection and overexpression and was attenuated by PCSK inhibitor treatment. Based upon our in vitro observation of specific apelin-13 production from apelin-55 by PCSK3 (Shin et al. 2013), it is likely that apelin-13 is produced and the resulting Hisapelin-55 $\Delta 13 \mathrm{~N}$-terminal domain is further processed by Arg exoproteases, such as carboxypeptidase $\mathrm{M}$ that is found on the surface of kidney cells (Skidgel et al. 1989). This would, in turn, produce the major observed product, Hisapelin-55 $\Delta 15$. Consistent with a steady-state level of this truncated $\mathrm{N}$-terminal domain production, the quantity of His-apelin-55 $\Delta 15$ did not significantly change upon pretreatment with either PCSK3 overexpression or PCSK inhibitor treatment.

Apelin-13 is also known to have a relatively short halflife $(<1 \mathrm{~h})$ in biological fluids such as plasma (Murza et al. 2012,2014 ), with a variety of medicinal chemistry-oriented research efforts specifically targeted at improving its stability (Narayanan et al. 2015). This is consistent with our inability to specifically isolate and observe apelin- 13 from culture medium through HPLC purification. Although it would certainly have been ideal to observe this isoform to unambiguously demonstrate this as the $\mathrm{C}$-terminal cleavage product, the most likely source of His-apelin-55 $\Delta 15$ is its production as the cleaved $\mathrm{N}$-terminal prodomain for apelin-13 by PCSK3.

The observation of His-apelin-55 32 as the second most prevalent $\mathrm{N}$-terminal domain fragment in HEK293A culture medium is less straightforward to link to PCSK3 activity. One possibility follows from the identification of apelin-31 both in bovine colostrum and milk (Mesmin et al. 2011) and, herein, in 3T3-L1 culture medium (Fig. S15). Extracellular processing to apelin-31-by some as yet-unidentified route-would, in turn, result in a product, His-apelin-55 $\Delta 31$, with a C-terminal Arg (Fig. 6) that could be processed by an Arg exoprotease to His-apelin-55 32 analogously to Hisapelin-55 13 to His-apelin-55 15 .

Consistent with the potential for a wide variety of extracellular processing events to occur, minor eluents were observed with masses corresponding to His-apelin-55 with both $\mathrm{N}$-terminal (19-30 residue) and C-terminal (15-16 residue) truncations. The exact sources of the wide variety of peptide products observed are hard to determine, but are consistent with the extensive catalog of apelin peptides seen in colostrum and milk (Mesmin et al. 2011). Because none of the related apelin isoforms themselves (i.e., apelin-13, $-15,-16$, or -32 ) were detected in the medium, any additional discussion would be even more speculative in nature. However, it is important to note that the lack or low levels of observable $\mathrm{C}$-terminal products is not unexpected given that bioactive $\mathrm{C}$-terminal apelin peptides have been shown to undergo rapid degradation in plasma (Murza et al. 2014), and with rates of degradation by the metalloprotease neprilysin being greater for the apelin-13 and -17 isoforms relative to apelin-36 (McKinnie et al. 2016). Despite this shortcoming in delineating the exact mechanism(s) of processing taking place, these results collectively demonstrate the potential for PCSK-dependent extracellular apelin processing employing HEK293A cells as a tractable model system.

Interestingly, pretreatment of HEK293 A cells with the PCSK inhibitor decanoyl-RVKR-CMK did not modify the level of His-apelin-55 15 resolved by HPLC, but resulted in the observation of a new major processing product consistent with His-apelin-55 1 (Fig. 6). Angiotensin-converting enzyme 2 (ACE2) (Vickers et al. 2002) and prolylcarboxypeptidase (PRCP) (Kehoe et al. 2016) have both been shown

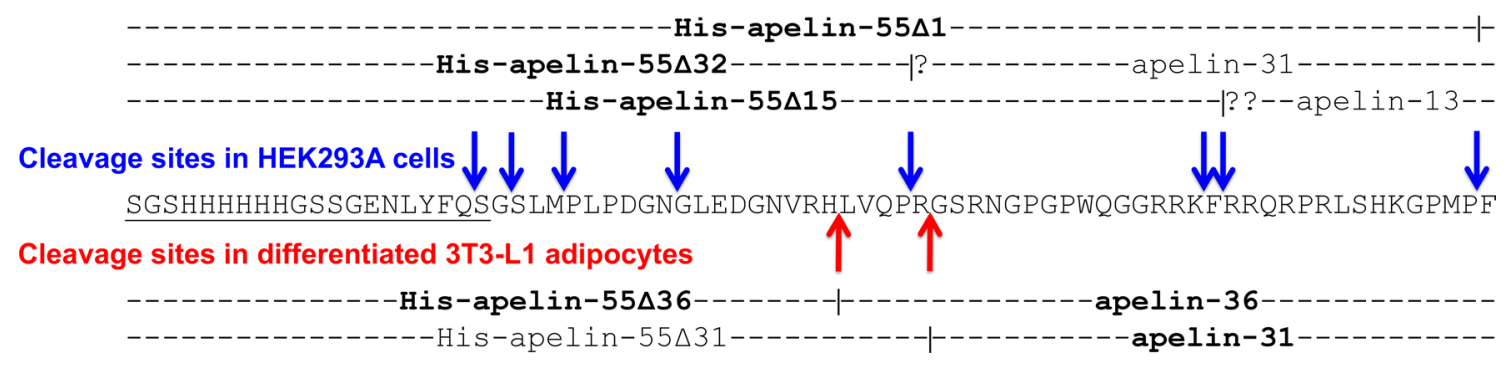

Fig. 6 Summary of His-apelin-55 processing based on cleavage products observed in HEK293A cell and 3T3-L1 adipocyte culture media. The primary observed $\mathrm{N}$ - and $\mathrm{C}$-terminal processing products are delineated, with bold type lettering distinguishing products observed by RP-HPLC and ESI-MS under the assay conditions. Arrows indi- cate all observed cleavage sites resolved upon incubation with each cell type. Question marks represent residues predicted to be removed as a result of further proteolytic cleavage. Underlined residues represent the $\mathrm{N}$-terminal $\mathrm{His}_{6}$ tag and TEV protease cleavage site 
to remove the C-terminal Phe of apelin in vitro. This has, in turn, been linked with deactivation and regulation in the apelinergic system (Ceraudo et al. 2014; Wang et al. 2016). Both ACE2 and PRCP are located on the cell surface and are expressed in kidney cells (Tipnis et al. 2000; ShariatMadar et al. 2002); thus, either (or both) may be responsible for the observed processing upon PCSK inhibition. Observation of this processed form only in the presence of inhibitor is notable for three reasons. First, observation of a major product other than His-apelin-55 $\Delta 15$, resulting from a well-characterized mechanism, unequivocally demonstrates the involvement of other proteases and underlines the nonproportional changes observed between the level of intact His-apelin-55 and new processed products. Second, it shows a direct and efficient truncation of the apelin C-terminal residue in HEK293A cell culture, likely hampering the ability to detect intact apelin isoforms. Third, the similar level of Hisapelin-55 15 observed with inhibitor treatment relative to without, despite the presence of an additional major processing product in the presence of inhibitor, further implies that the processes involved in regulation of His-apelin-55 $\Delta 15$ levels are leading to steady-state behavior.

The 3T3-L1 adipocyte cell line has previously been employed for characterization of physiological roles of apelin such as adipogenesis, lipolysis, and glucose homeostasis (Than et al. 2012; Zhu et al. 2011). Thus, it is highly noteworthy that incubation of His-apelin-55 with 3T3-L1 adipocytes resulted in a clearly distinct processing pattern relative to with HEK293A cells, with the primary N-terminal cleavage product observed being His-apelin-55 $\Delta 36$. Correspondingly, apelin-36 was directly detected. Apelin-31 was also detected, suggesting that multiple forms of processing take place and, potentially, tying to the observation of His-apelin$55 \Delta 32$ in HEK293A culture medium.

Despite endogenous PCSK3 expression in 3T3-L1 cells (Shin et al. 2013), these results imply that the processing of apelin in 3T3-L1 medium is likely primarily due to PCSKs other than PCSK3 or through PCSK-like endoproteases that are either not present or relatively inactive in HEK293A cells. Subsequently, this as yet-unidentified endoprotease may be present at relatively low levels or have higher sensitivity to decanoyl-RVKR-CMK, resulting in the tenfold decrease in minimum inhibitor concentration observed between cell lines.

As an alternative to extracellular processing, a mechanism could be envisioned where His-apelin-55 is internalized through receptor-mediated endocytosis or another endocytic pathway, processed intracellularly, and then secreted. Such mechanisms would be highly energy intensive and are difficult to reconcile with the degree of apelin processing observed in both culture media. Correspondingly, we are unaware of such a mechanism having been previously observed. Furthermore, examples of exactly the opposite behavior have been documented, where proproteins are secreted and specifically rely on processing by cell surface PCSK3 (Koo et al. 2006; Xiao et al. 2008). Receptor-mediated trafficking and subsequent intracellular processing is also unlikely to occur, given, as noted above, the negative correlation of apelin-AR dissociation to isoform length and the fact that apelin-36 exhibits a sustained receptor interaction leading to receptor degradation (Lee et al. 2010). Observation of an anionic surface on the AR extracellular domain (Ma et al. 2017) is correlated with this potential for favourable ligand-receptor binding (Shin et al. 2018). Apelin-55, thus, seems likely to follow the precedent of apelin-36 with favourable binding to the receptor that would prevent processing through steric hindrance, occlusion of the proteolytic site, and/or limiting of the quantity of free apelin-55. Furthermore, while 3T3-L1 adipocytes express AR (Attane et al. 2011), HEK293A cells do not (Bai et al. 2014a, b). An AR-mediated mechanism of internalization would thus be possible for 3T3-L1 adipocytes, but not HEK293A cells.

In conclusion, extracellular apelin processing is both possible and highly probable. Through extracellular processing, a mechanism may be envisioned where longer apelin isoforms (e.g., apelin-55 or -36) in circulation are processed to specific isoform(s) at an appropriate location to exert the isoform-specific physiological responses observed previously (Adam et al. 2016; Galon-Tilleman et al. 2017). This is also consistent with preferential tissue-dependent apelin isoform enrichment (Kawamata et al. 2001; De Mota et al. 2004). Given the known differences in potency, efficacy, and in downstream effects, controlling apelin processing through the activity of specific cell surface enzymes would serve to provide an additional level of regulation in directing downstream effects. Such processing-mediated regulation may not be limited to apelin, with the recent identification of apela (ELABELA (Chng et al. 2013)/Toddler (Pauli et al. 2014)) as a second endogenous peptidic ligand for the AR. Like apelin, apela can be processed into multiple N-terminally truncated forms with isoform-dependent functional properties (Shin et al. 2018), implying the potential for similar regulation. In combination with the previously demonstrated potential of intracellular apelin processing, extracellular processing of apelinergic system ligands is indicative of the involvement of diverse mechanisms and proteases in regulation of the apelinergic system.

Acknowledgements Thanks to Xiao Feng (Dalhousie Mass Spectrometry Laboratory) and Bruce Stewart for their expert technical support. This work was supported by Canadian Institutes of Health Research (CIHR) Operating Grants (MOP-111138 to JKR and MOP-82795 to YA) and the IWK Research Foundation (Category B to YA). Key equipment was provided through the Natural Sciences and Engineering Research Council of Canada (NSERC) and Dalhousie Medical Research Foundation. KS held an NSERC Alexander Graham Bell Canadian Graduate Scholarship and a Killam Predoctoral Scholarship; JKR was supported by a CIHR New Investigator Award. 


\section{Compliance with ethical standards}

Conflict of interest The authors report no relationships or interests that would lead to a bias or undue influence.

Research involving human participants and/or animals None.

\section{References}

Adam F, Khatib AM, Lopez JJ, Vatier C, Turpin S, Muscat A, Soulet F, Aries A, Jardin I, Bobe R, Stepanian A, de Prost D, Dray C, Rosado JA, Valet P, Feve B, Siegfried G (2016) Apelin: an antithrombotic factor that inhibits platelet function. Blood 127(7):908-920. https://doi.org/10.1182/blood-2014-05-578781

Attane C, Daviaud D, Dray C, Dusaulcy R, Masseboeuf M, Prevot D, Carpene C, Castan-Laurell I, Valet P (2011) Apelin stimulates glucose uptake but not lipolysis in human adipose tissue ex vivo. J Mol Endocrinol 46(1):21-28. https://doi.org/10.1677/ JME-10-0105

Azizi M, Iturrioz X, Blanchard A, Peyrard S, De Mota N, Chartrel N, Vaudry H, Corvol P, Llorens-Cortes C (2008) Reciprocal regulation of plasma apelin and vasopressin by osmotic stimuli. J Am Soc Nephrol 19(5):1015-1024. https://doi.org/10.1681/ ASN.2007070816

Bai B, Cai X, Jiang Y, Karteris E, Chen J (2014a) Heterodimerization of apelin receptor and neurotensin receptor 1 induces phosphorylation of ERK and cell proliferation via Galphaq-mediated mechanism. J Cell Mol Med 18(1):2071-2081. https://doi.org/10.1111/ jemm.12404

Bai B, Liu L, Zhang N, Wang C, Jiang Y, Chen J (2014b) Heterodimerization of human apelin and bradykinin 1 receptors: novel signal transduction characteristics. Cell Signal 26(7):1549-1559. https://doi.org/10.1016/j.cellsig.2014.03.022

Ceraudo E, Galanth C, Carpentier E, Banegas-Font I, Schonegge AM, Alvear-Perez R, Iturrioz X, Bouvier M, Llorens-Cortes C (2014) Biased signaling favoring $\mathrm{G}_{\mathrm{i}}$ over $\beta$-arrestin promoted by an apelin fragment lacking the $\mathrm{C}$-terminal phenylalanine. J Biol Chem 289(35):24599-24610. https://doi.org/10.1074/jbc.M113.541698

Chng SC, Ho L, Tian J, Reversade B (2013) ELABELA: a hormone essential for heart development signals via the apelin receptor. Dev Cell 27(6):672-680. https://doi.org/10.1016/j.devce 1.2013.11.002

De Mota N, Reaux-Le Goazigo A, El Messari S, Chartrel N, Roesch D, Dujardin C, Kordon C, Vaudry H, Moos F, Llorens-Cortes C (2004) Apelin, a potent diuretic neuropeptide counteracting vasopressin actions through inhibition of vasopressin neuron activity and vasopressin release. Proc Natl Acad Sci USA 101(28):1046410469. https://doi.org/10.1073/pnas.0403518101

Dray C, Sakar Y, Vinel C, Daviaud D, Masri B, Garrigues L, Wanecq E, Galvani S, Negre-Salvayre A, Barak LS, Monsarrat B, BurletSchiltz O, Valet P, Castan-Laurell I, Ducroc R (2013) The intestinal glucose-apelin cycle controls carbohydrate absorption in mice. Gastroenterology 144(4):771-780. https://doi.org/10.1053/j.gastr o.2013.01.004

Evans NA, Groarke DA, Warrack J, Greenwood CJ, Dodgson K, Milligan G, Wilson S (2001) Visualizing differences in ligandinduced $\beta$-arrestin-GFP interactions and trafficking between three recently characterized $G$ protein-coupled receptors. J Neurochem 77(2):476-485

Foldes G, Horkay F, Szokodi I, Vuolteenaho O, Ilves M, Lindstedt KA, Mayranpaa M, Sarman B, Seres L, Skoumal R, Lako-Futo Z, deChatel R, Ruskoaho H, Toth M (2003) Circulating and cardiac levels of apelin, the novel ligand of the orphan receptor APJ, in patients with heart failure. Biochem Biophys Res Commun 308(3):480-485

Galon-Tilleman H, Yang H, Bednarek MA, Spurlock SM, Paavola KJ, Ko B, To C, Luo J, Tian H, Jermutus L, Grimsby J, Rondinone CM, Konkar A, Kaplan DD (2017) Apelin-36 modulates blood glucose and body weight independently of canonical APJ receptor signaling. J Biol Chem 292(5):1925-1933. https://doi. org/10.1074/jbc.M116.748103

Gill SC, von Hippel PH (1989) Calculation of protein extinction coefficients from amino acid sequence data. Anal Biochem 182(2):319-326

Habata Y, Fujii R, Hosoya M, Fukusumi S, Kawamata Y, Hinuma S, Kitada C, Nishizawa N, Murosaki S, Kurokawa T, Onda H, Tatemoto K, Fujino M (1999) Apelin, the natural ligand of the orphan receptor APJ, is abundantly secreted in the colostrum. Biochim Biophys Acta 1452(1):25-35

Kawamata Y, Habata Y, Fukusumi S, Hosoya M, Fujii R, Hinuma S, Nishizawa N, Kitada C, Onda H, Nishimura O, Fujino M (2001) Molecular properties of apelin: tissue distribution and receptor binding. Biochim Biophys Acta 1538(2-3):162-171

Kehoe K, Van Elzen R, Verkerk R, Sim Y, Van der Veken P, Lambeir AM, De Meester I (2016) Prolyl carboxypeptidase purified from human placenta: its characterization and identification as an apelin-cleaving enzyme. Biochim Biophys Acta 1864(11):14811488. https://doi.org/10.1016/j.bbapap.2016.07.004

Kleinz MJ, Davenport AP (2005) Emerging roles of apelin in biology and medicine. Pharmacol Ther 107(2):198-211. https://doi. org/10.1016/j.pharmthera.2005.04.001

Klimpel KR, Molloy SS, Thomas G, Leppla SH (1992) Anthrax toxin protective antigen is activated by a cell surface protease with the sequence specificity and catalytic properties of furin. Proc Natl Acad Sci USA 89(21):10277-10281

Koo BH, Longpre JM, Somerville RP, Alexander JP, Leduc R, Apte SS (2006) Cell-surface processing of pro-ADAMTS9 by furin. J Biol Chem 281(18):12485-12494. https://doi.org/10.1074/jbc. M511083200

Langelaan DN, Rainey JK (2009) Headgroup-dependent membrane catalysis of apelin-receptor interactions is likely. J Phys Chem B 113(30):10465-10471. https://doi.org/10.1021/jp904562q

Lee DK, Ferguson SS, George SR, O'Dowd BF (2010) The fate of the internalized apelin receptor is determined by different isoforms of apelin mediating differential interaction with $\beta$-arrestin. Biochem Biophys Res Commun 395(2):185-189. https://doi.org/10.1016/j. bbrc.2010.03.151

Ma Y, Yue Y, Ma Y, Zhang Q, Zhou Q, Song Y, Shen Y, Li X, Ma X, Li C, Hanson MA, Han GW, Sickmier EA, Swaminath G, Zhao S, Stevens RC, Hu LA, Zhong W, Zhang M, Xu F (2017) Structural basis for apelin control of the human apelin receptor. Structure 25(6):858-866 e854. https://doi.org/10.1016/j. str.2017.04.008

Masaki T, Yasuda T, Yoshimatsu H (2012) Apelin-13 microinjection into the paraventricular nucleus increased sympathetic nerve activity innervating brown adipose tissue in rats. Brain Res Bull 87(6):540-543. https://doi.org/10.1016/j.brainresbull.2012.02.004

Mayer G, Boileau G, Bendayan M (2003) Furin interacts with proMT1MMP and integrin $\alpha \mathrm{V}$ at specialized domains of renal cell plasma membrane. J Cell Sci 116(9):1763-1773. https://doi.org/10.1242/ jcs.00394

Mayer G, Boileau G, Bendayan M (2004) Sorting of furin in polarized epithelial and endothelial cells: expression beyond the Golgi apparatus. J Histochem Cytochem 52(5):567-579. https://doi. org/10.1177/002215540405200502

McKinnie SM, Fischer C, Tran KM, Wang W, Mosquera F, Oudit GY, Vederas JC (2016) The metalloprotease neprilysin degrades and inactivates apelin peptides. ChemBioChem 17(16):1495-1498. https://doi.org/10.1002/cbic.201600244 
Mesmin C, Fenaille F, Becher F, Tabet JC, Ezan E (2011) Identification and characterization of apelin peptides in bovine colostrum and milk by liquid chromatography-mass spectrometry. J Proteome Res 10(11):5222-5231. https://doi.org/10.1021/pr200725x

Miettinen KH, Magga J, Vuolteenaho O, Vanninen EJ, Punnonen KR, Ylitalo K, Tuomainen P, Peuhkurinen KJ (2007) Utility of plasma apelin and other indices of cardiac dysfunction in the clinical assessment of patients with dilated cardiomyopathy. Regul Pept 140(3):178-184. https://doi.org/10.1016/j.regpep.2006.12.004

Molloy SS, Anderson ED, Jean F, Thomas G (1999) Bi-cycling the furin pathway: from TGN localization to pathogen activation and embryogenesis. Trends Cell Biol 9(1):28-35

Murza A, Parent A, Besserer-Offroy E, Tremblay H, Karadereye F, Beaudet N, Leduc R, Sarret P, Marsault E (2012) Elucidation of the structure-activity relationships of apelin: influence of unnatural amino acids on binding, signaling, and plasma stability. ChemMedChem 7(2):318-325. https://doi.org/10.1002/cmdc.201100492

Murza A, Belleville K, Longpre JM, Sarret P, Marsault E (2014) Stability and degradation patterns of chemically modified analogs of apelin-13 in plasma and cerebrospinal fluid. Biopolymers 102(4):297303. https://doi.org/10.1002/bip.22498

Narayanan S, Harris DL, Maitra R, Runyon SP (2015) Regulation of the apelinergic system and Its potential in cardiovascular disease: peptides and small molecules as tools for discovery. J Med Chem 58(20):7913-7927. https://doi.org/10.1021/acs.jmedchem.5b00527

Pauli A, Norris ML, Valen E, Chew GL, Gagnon JA, Zimmerman S, Mitchell A, Ma J, Dubrulle J, Reyon D, Tsai SQ, Joung JK, Saghatelian A, Schier AF (2014) Toddler: an embryonic signal that promotes cell movement via Apelin receptors. Science 343(6172): 1248636. https://doi.org/10.1126/science.1248636

Remacle AG, Gawlik K, Golubkov VS, Cadwell GW, Liddington RC, Cieplak P, Millis SZ, Desjardins R, Routhier S, Yuan XW, Neugebauer WA, Day R, Strongin AY (2010) Selective and potent furin inhibitors protect cells from anthrax without significant toxicity. Int J Biochem Cell Biol 42(6):987-995. https://doi.org/10.1016/j.bioce 1.2010 .02 .013

Sargent DF, Schwyzer R (1986) Membrane lipid phase as catalyst for peptide-receptor interactions. Proc Natl Acad Sci USA 83(16):5774-5778

Seidah NG (2011) The proprotein convertases, 20 years later. Methods Mol Biol 768:23-57. https://doi.org/10.1007/978-1-61779-204-5_3

Seidah NG, Prat A (2012) The biology and therapeutic targeting of the proprotein convertases. Nat Rev Drug Discov 11(5):367-383

Semenov AG, Tamm NN, Seferian KR, Postnikov AB, Karpova NS, Serebryanaya DV, Koshkina EV, Krasnoselsky MI, Katrukha AG (2010) Processing of pro-B-type natriuretic peptide: furin and corin as candidate convertases. Clin Chem 56(7):1166-1176. https://doi. org/10.1373/clinchem.2010.143883

Shariat-Madar Z, Mahdi F, Schmaier AH (2002) Identification and characterization of prolylcarboxypeptidase as an endothelial cell prekallikrein activator. J Biol Chem 277(20):17962-17969. https:// doi.org/10.1074/jbc.M106101200

Shin K, Chapman NA, Sarker M, Kenward C, Huang SK, WeatherbeeMartin N, Pandey A, Dupre DJ (1861) Rainey JK (2017a) Bioactivity of the putative apelin proprotein expands the repertoire of apelin receptor ligands. Biochim Biophys Acta 8:1901-1912. https://doi. org/10.1016/j.bbagen.2017.05.017

Shin K, Pandey A, Liu XQ, Anini Y, Rainey JK (2013) Preferential apelin-13 production by the proprotein convertase PCSK3 is implicated in obesity. FEBS Open Bio 3:328-333. https://doi.org/10.1016/j. fob.2013.08.001

Shin K, Sarker M, Huang SK, Rainey JK (2017) Apelin conformational and binding equilibria upon micelle interaction primarily depend on membrane-mimetic headgroup. Sci Rep 7(1):15433. https://doi. org/10.1038/s41598-017-14784-0
Shin K, Kenward C, Rainey JK (2018) Apelinergic system structure and function. Compr Physiol 8(1):407-450. https://doi.org/10.1002/ cphy.c170028

Skidgel RA, Davis RM, Tan F (1989) Human carboxypeptidase M. Purification and characterization of a membrane-bound carboxypeptidase that cleaves peptide hormones. J Biol Chem 264(4):2236-2241

Tatemoto K, Hosoya M, Habata Y, Fujii R, Kakegawa T, Zou MX, Kawamata Y, Fukusumi S, Hinuma S, Kitada C, Kurokawa T, Onda H, Fujino M (1998) Isolation and characterization of a novel endogenous peptide ligand for the human APJ receptor. Biochem Biophys Res Commun 251(2):471-476. https://doi.org/10.1006/ bbrc.1998.9489

Teuchert M, Berghofer S, Klenk HD, Garten W (1999) Recycling of furin from the plasma membrane. Functional importance of the cytoplasmic tail sorting signals and interaction with the AP-2 adaptor medium chain subunit. J Biol Chem 274(51):36781-36789

Than A, Cheng Y, Foh LC, Leow MK, Lim SC, Chuah YJ, Kang Y, Chen $\mathrm{P}$ (2012) Apelin inhibits adipogenesis and lipolysis through distinct molecular pathways. Mol Cell Endocrinol 362(1-2):227-241. https ://doi.org/10.1016/j.mce.2012.07.002

Than A, He HL, Chua SH, Xu D, Sun L, Leow MK, Chen P (2015) Apelin enhances brown adipogenesis and browning of white adipocytes. J Biol Chem 290(23):14679-14691. https://doi.org/10.1074/ jbc.M115.643817

Thomas G (2002) Furin at the cutting edge: from protein traffic to embryogenesis and disease. Nat Rev Mol Cell Biol 3(10):753-766. https ://doi.org/10.1038/nrm934

Tipnis SR, Hooper NM, Hyde R, Karran E, Christie G, Turner AJ (2000) A human homolog of angiotensin-converting enzyme. Cloning and functional expression as a captopril-insensitive carboxypeptidase. J Biol Chem 275(43):33238-33243. https://doi.org/10.1074/jbc. m002615200

Vickers C, Hales P, Kaushik V, Dick L, Gavin J, Tang J, Godbout K, Parsons T, Baronas E, Hsieh F, Acton S, Patane M, Nichols A, Tummino P (2002) Hydrolysis of biological peptides by human angiotensin-converting enzyme-related carboxypeptidase. J Biol Chem 277(17):14838-14843. https://doi.org/10.1074/jbc.M200581200

Vidricaire G, Denault JB, Leduc R (1993) Characterization of a secreted form of human furin endoprotease. Biochem Biophys Res Commun 195(2):1011-1018. https://doi.org/10.1006/bbrc.1993.2145

Wang W, McKinnie SM, Farhan M, Paul M, McDonald T, McLean B, Llorens-Cortes C, Hazra S, Murray AG, Vederas JC, Oudit GY (2016) Angiotensin-converting enzyme 2 metabolizes and partially inactivates pyr-apelin-13 and apelin-17: physiological effects in the cardiovascular system. Hypertension 68(2):365-377. https://doi. org/10.1161/HYPERTENSIONAHA.115.06892

Xiao Y, Chen G, Richard J, Rougeau N, Li H, Seidah NG, Cohen EA (2008) Cell-surface processing of extracellular human immunodeficiency virus type $1 \mathrm{Vpr}$ by proprotein convertases. Virology 372(2):384-397. https://doi.org/10.1016/j.virol.2007.10.036

Yue P, Jin H, Xu S, Aillaud M, Deng AC, Azuma J, Kundu RK, Reaven GM, Quertermous T, Tsao PS (2011) Apelin decreases lipolysis via $\mathrm{G}_{\mathrm{q}}, \mathrm{G}_{\mathrm{i}}$, and AMPK-dependent mechanisms. Endocrinology 152(1):59-68. https://doi.org/10.1210/en.2010-0576

Zhen EY, Higgs RE, Gutierrez JA (2013) Pyroglutamyl apelin-13 identified as the major apelin isoform in human plasma. Anal Biochem 442(1):1-9. https://doi.org/10.1016/j.ab.2013.07.006

Zhu S, Sun F, Li W, Cao Y, Wang C, Wang Y, Liang D, Zhang R, Zhang $\mathrm{S}$, Wang H, Cao F (2011) Apelin stimulates glucose uptake through the PI3 K/Akt pathway and improves insulin resistance in 3T3L1 adipocytes. Mol Cell Biochem 353(1-2):305-313. https://doi. org/10.1007/s11010-011-0799-0 